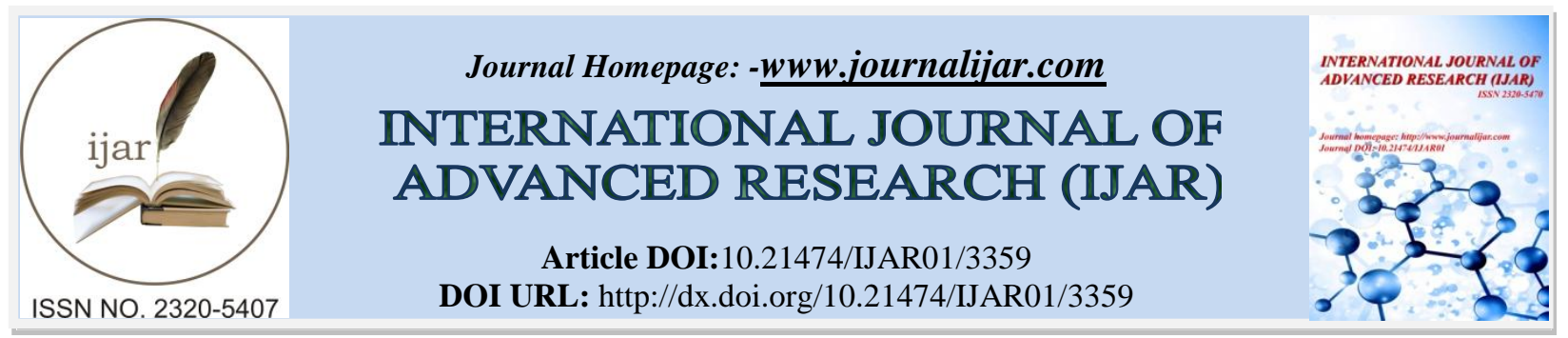

RESEARCH ARTICLE

\title{
A SURVEY ON PUBLIC AWARENESS ABOUT THE ROLE OF ANESTHESIOLOGISTS
}

\author{
Abdullah S. Alqefari,Abdullah A. alyami, Tarik M. Almowald, Faisal M. Alturi, Mousa R. Alhokail, \\ Mohammed A. Alqhtani, Jamal A. Alghamdi, Naif S. Alotaibi, Maha A. Alenezi, MohammedA.Alkahmous, \\ Abdulaziz A. Alkahmous and Omar A. Ahmed. \\ GPs, College of Medicine, Jordanian University of Science and Technology (JUST), Riyadh, KSA.
}

\section{Manuscript Info}

\section{Manuscript History}

Received: 22 December 2016

Final Accepted: 26 January 2017

Published: February 2017

Key words:-

Anesthesiology, Anesthesiologists' roles, Anesthesia

\begin{abstract}
Background:Anesthesiology is a medical discipline and the specialist of this science is the anesthesiologist. The roles of anesthesiologists are not obvious to most of public, although their roles are very important and critical. The roles of anesthesiologistsexceed the limitation of operating room, they have many roles preoperatively and postoperatively. More awareness about their roles is necessary. Patients may become more relaxed when they know their anesthesiologistand identify his role in their safety and success of their surgery.

Aim:The objective of this study is too assess the public knowledge about the role of anesthesiologist and to educate the public.

Methods:This study included 202 patients to answer 10 questions about their knowledge regarding anesthesiologist and anesthesia using simple and short questionnaire.

Results:Most of patients in this study had good knowledge about anesthesiologist and most percentages of positive answers were high .No association between awareness of patients and gender was found.

Conclusion:Patients had good and acceptable knowledge about the role of anesthesiologist.
\end{abstract}

Copy Right, IJAR, 2017,. All rights reserved.

\section{Introduction:-}

Anesthesia has developed after the first anesthesia was administered by TG Morton in 1846, it has a supportive role in performing advanced surgeries (Ribeiro et al, 2015). Anesthesiology is one of medical Science branches (Sable et al, 2016), it has been grown in the recent pastyears(Cooper et al, 1995), by development of monitoring system, new anesthetic agents and techniques (Khara et al, 2013), however it is behind the light, the knowledge about this specialty and the exact role of anesthesiologists is limited between public(Cooper et al, 1995).After the great advances in anesthesia field (Lee et al, 2014), now anesthesiologists play a very important role in peri-operative, the operating room, intensive care, trauma centers,pain management and on the code team(Lee et al, 2014; Prasad et al, 2014; Kadriet al, 2014), however they don't receive the deserved attention andtheir due regards between public (Prasad et al, 2014), this limited awareness of public about the anesthesiologist exceeds anesthesiologist's role in the operating room (Ribeiro et al, 2015), reaching to anesthetist's roles outside the operation room (Garry, 2001).This lack in public awareness about anesthetist's role is not new (Armitage, 1978). Many studies have reported a low public awareness about anesthesia and the role of anesthetists in both developing and developed countries (Swinhoe et al, 1994; Jathar et al, 2002).Patients think that the surgeon is responsible for tasks of anesthesia(Acosta-Martínez et al, 2016),44.5\% think so, while only $22 \%$ of them know that anesthesiologistswere the providers of anesthesia 
(Sable et al, 2016)but inanother report $42 \%$ of patients knew that the anesthetist was responsible for providing anesthesia(Naod et al, 2016)this still low percent. Actually patients don't know if the anesthesiologist is even a physician(Erdenet al, 2012), but it was reported that $67 \%$ ofsurvey respondents in a survey conducted in the United Kingdom during knew that anesthesiologist is a doctor(Keep et al, 1978), while this percent raised in 1933 to reach $81 \%$ and then dropped again in 1994 to $65 \%$ (Swinhoe et al, 1994; Hennessy et al, 1993). These results seems quite good, but in developing countries this percent is low (Hariharan, 2009).In Pakistanonly 56\% of the patients hadknown that anesthesiologist is a physician (Khan et al, 1999). Here in Saudi Arabia $50 \%$ of the patients had the awareness about the previous fact (Baaj et al, 2006).Beside that other patients did not know thatanesthesiologists are responsible for monitoring their vital signs throughout surgery, only $27.33 \%$ of the patients knewthat role.Also a limited number of patients had the knowledge aboutanesthesiologist's role in intensive care unit (ICU), painless labor and relief of chronic pain with percentage 7.33\%, 12.67\%and 4.67\% respectively (Naithani et al, 2007).The reason for the poor knowledge may be related to anesthetists being busy in operating room and they have limited time to interact with their patients' pre \& post-operatively(Naod et al, 2016).Not only is the role of anesthetists neglected by patients, but also by others such as administrative staff in the hospitals who did not see the importance of this specialty (Hariharan, 2009). The Audit Commission in Englanddid not realize any role for anesthesiologists outside the operating room (Pleuvry et al, 1982)and in some universities all over the world,they see that there is no requirement for anesthesiologyto be taught for medical students (Cheunget al, 1999).A widehealth care awareness especially in developed countries has been taken place(Khara et al, 2013).Public awareness programs were arranged in developed countries for increasing public knowledge about the anesthetists(Khara et al, 2013;Prasad et al, 2014; ,Pandyaet al, 2016; Ahsan- Ul-Haq et al, 2004). October 16th is celebrated as Anesthesia Day worldwide (Prasad et al, 2014; Pandyaet al, 2016), this explains why the developed countries have high care awareness among the patients (Bhandary et al, 2016).It is important especially in our countries to spread the awareness and knowledge about anesthesiologists, so in this study we assess the public knowledge about the roleofanesthesiologists.

\section{Materials and Methods:-}

\section{Subjects:-}

This cross sectional observational study was performed on 202 patients in the period from $20^{\text {th }}$ January 2017 to $7^{\text {th }}$ February2017 from Yamama Hospital in Riyadh, an approval from thehospital was obtained to perform this study. This study was performed after operation performing. Patients accepted to answer questions, theywere not exposed to any pressure andthey freely answered the questions, there was no exclusion for patients.

\section{Questionnaire:-}

A questionnaire was established to record patients' answers. It was containing 10 questions written in both Arabic and English. The answers were recorded as Yes and No in the questionnaire to be easy for patients.

\section{Statistical analysis:-}

Data were analyzed by using Statistical Package for Social Studies (SPSS 22; IBM Corp., New York, NY, USA). Continuous variables were expressed as mean \pm standard deviation and categorical variables were expressed as percentages. Chi square test was used for categorical variables. P-value $<0.05$ was considered statistically significant.

\section{Results:-}

This study was conducted on 202 patients after performing operation. The number of males was 69 (34.16\%) while females' number was $133(65.84 \%)$, the female represents most of patients in this study. The mean age of participants was 32.84 \pm 10.94 . Most of the individuals were Saudi $184(91.1 \%)$ and few of participants were non Saudi $18(8.9 \%)$. The majority of patients were from urban areas $197(97.5 \%)$ and only $5(2.5 \%)$ came from rural area. The questions of questionnaire are summarized in table1. 
Table 1:- Questions presented to patients

\begin{tabular}{|l|l|}
\hline Item No & Questions \\
\hline Q1 & Do you know what anaesthesiais? \\
\hline Q2 & Do you know that anaesthesiologists are doctors? \\
\hline Q3 & Do you know that anaesthesia is safe? \\
\hline Q4 & Do you Know that there are different types of anaesthesia for different surgeries? \\
\hline Q5 & Do you Know that, unless you give informed consent, nothing is performed? \\
\hline Q6 & Do you Know that all types of pain can be managed by anaesthesiologists? \\
\hline Q7 & Do you Know that labour can be painless with labour analgesia? \\
\hline Q8 & Would you prefer painless delivery? (Female only) \\
\hline Q9 & Would you know that you should follow certain preoperative instructions? \\
\hline Q10 & Did you have any benefit by visiting anaesthesia stall in this mela? \\
\hline
\end{tabular}

The answers were recorded as yes and no and percent of each answer was estimated. Figure1High percent of participants knew about anesthesia $87.62 \%$, most of patients $82.67 \%$ knew that anesthesiologist is a doctor. $70.30 \%$ of them realized that anesthesia is safe and $61.88 \%$ had knowledge about different types of anesthesia. $72.77 \%$ of patients knew about the consent, more than half of patients $64.85 \%$ knew that anesthesiologist can manage all types of pains. Only $11.88 \%$ did not know about painless labor. Most of females in this study preferred painless delivery $88.72 \%$ than painful one. The majority of individuals $92.08 \%$ knew that there are certain preoperative instructionsshould be followed and $72.77 \%$ found benefit by visiting anesthesia stall.

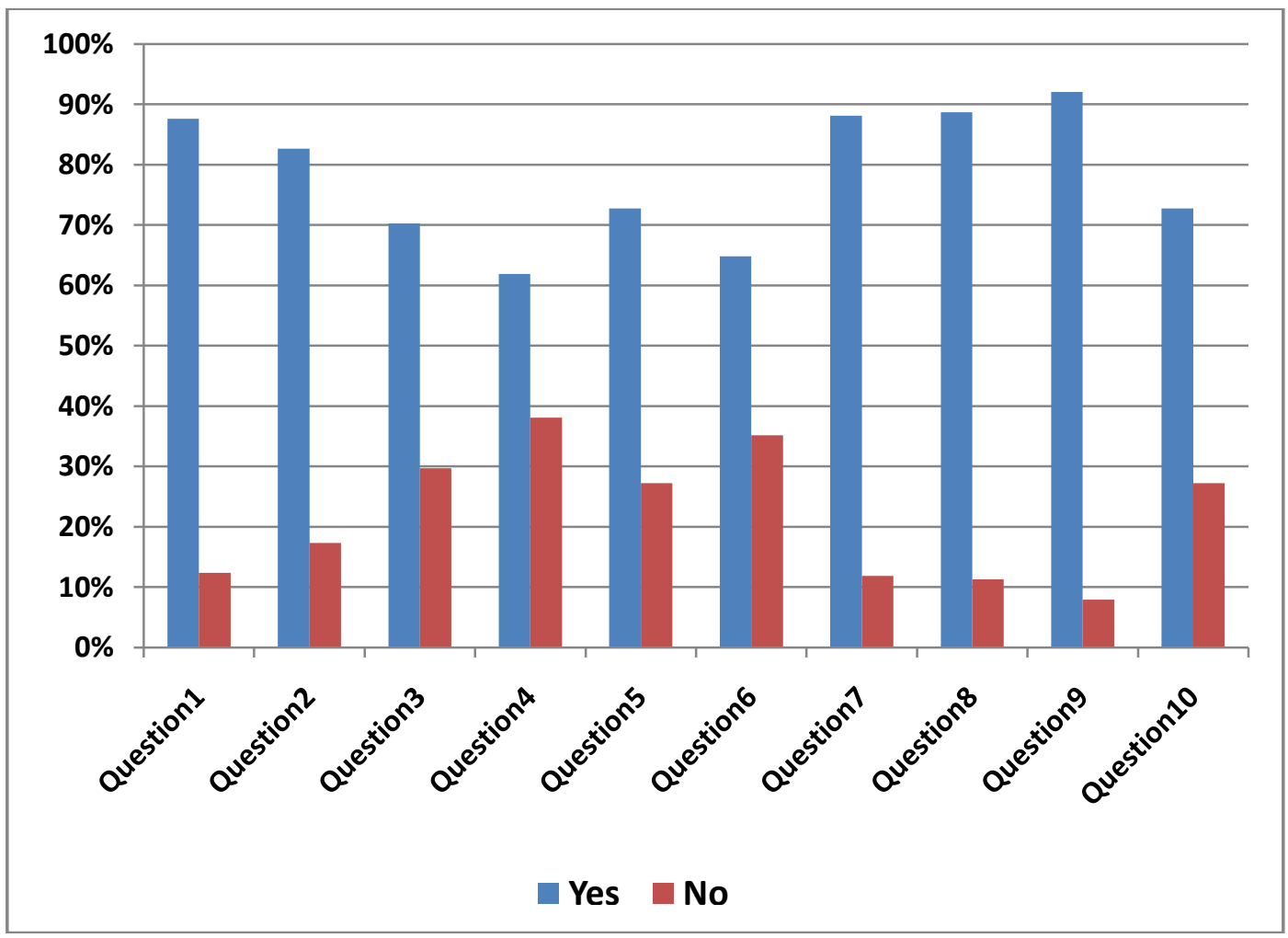

Fig 1:- Answers of patients to the questions

There was no significant difference in all answers regarding gender except for question number2, where females had more knowledge than males about anesthesiologist as a doctor. Table2. 
Table 2:- Participants' answers to the questionnaire by gender.

\begin{tabular}{|c|c|c|c|c|c|c|}
\hline \multirow{2}{*}{$\begin{array}{l}\text { Item } \\
\text { No }\end{array}$} & \multirow[t]{2}{*}{ Question } & \multicolumn{2}{|l|}{ Male } & \multicolumn{2}{|l|}{ Female } & \multirow[t]{2}{*}{ *P-value } \\
\hline & & Yes (\%) & $\operatorname{No}(\%)$ & Yes( $(\%)$ & $\mathrm{No}(\%)$ & \\
\hline Q1 & Do you know what anaesthesia is? & $\begin{array}{l}61 \\
(88.41)\end{array}$ & $8(11.59)$ & $\begin{array}{l}116 \\
(87.22)\end{array}$ & $17(12.78)$ & 0.808 \\
\hline $\mathrm{Q} 2$ & $\begin{array}{l}\text { Do you know that } \\
\text { anaesthesiologists are doctors? }\end{array}$ & $(75.36) 52$ & 17 (24.64) & $\begin{array}{l}115 \\
(86.47)\end{array}$ & $18(13.53)$ & 0.048 \\
\hline Q3 & $\begin{array}{l}\text { Do you know that anaesthesia is } \\
\text { safe? }\end{array}$ & $\begin{array}{l}46 \\
(66.67)\end{array}$ & $23(33.33)$ & $96(72.18)$ & $37(27.82)$ & 0.416 \\
\hline Q4 & $\begin{array}{l}\text { Do you Know that there are } \\
\text { different types of anaesthesia for } \\
\text { different surgeries? }\end{array}$ & $\begin{array}{l}41 \\
(59.42)\end{array}$ & $28(40.58)$ & $84(63.16)$ & $49(36.84)$ & 0.604 \\
\hline Q5 & $\begin{array}{l}\text { Do you Know that, unless you } \\
\text { give informed consent, nothing is } \\
\text { performed? }\end{array}$ & $\begin{array}{l}48 \\
(69.57)\end{array}$ & $21(30.43)$ & $99(74.44)$ & $34(25.56)$ & 0.461 \\
\hline Q6 & $\begin{array}{l}\text { Do you Know that all types of } \\
\text { pain can be managed by } \\
\text { anaesthesiologists? }\end{array}$ & $\begin{array}{l}48 \\
(69.57)\end{array}$ & $21(30.43)$ & $83(62.41)$ & $50(37.59)$ & 0.312 \\
\hline Q7 & $\begin{array}{l}\text { Do you Know that labour can be } \\
\text { painless with labour analgesia? }\end{array}$ & $\begin{array}{l}57 \\
(82.61)\end{array}$ & 12 (17.39) & $\begin{array}{l}121 \\
(90.98)\end{array}$ & $12(9.02)$ & 0.081 \\
\hline Q8 & $\begin{array}{l}\text { Would you prefer painless } \\
\text { delivery? (Female only) }\end{array}$ & - & & $\begin{array}{l}118 \\
(88.72)\end{array}$ & $15(11.28)$ & - \\
\hline Q9 & $\begin{array}{l}\text { Would you know that you should } \\
\text { follow certain preoperative } \\
\text { instructions? }\end{array}$ & $\begin{array}{l}62 \\
(89.86)\end{array}$ & $\begin{array}{ll}7 & (10.14)\end{array}$ & $\begin{array}{l}124 \\
(93.23)\end{array}$ & $9(6.77)$ & 0.399 \\
\hline Q10 & $\begin{array}{l}\text { Did you have any benefit by } \\
\text { visiting anaesthesia stall in this } \\
\text { mela? }\end{array}$ & $\begin{array}{l}50 \\
(72.46)\end{array}$ & $19(27.54)$ & $97(72.93)$ & $36(27.07)$ & 0.943 \\
\hline
\end{tabular}

*P-value $<0.05$ was statistically significant.

\section{Discussion:-}

Complex surgery is now possible and easier due to developed techniques by anesthetists (Naod et al, 2016), indeed the role of anesthesiologist not only inside the operating room, but also in preoperative evaluation, pain management and intensive care(Erden et al, 2012). However public awareness about anesthesiologist is low. In the present study we investigated about the knowledge of patients about anesthesiologist and anesthesia, we found that most of participants $87.62 \%$ knew about anesthesia, this is a high percent compared to many other studies (Prasad et al, 2014; Swinhoe et al, 1994; Ismaeil, 2011) where the percentage of people knew about anesthesia were $82 \%, 80 \%$ and $60.6 \%$. In another study (Pandyaet al, 2016) only 26\% of participants knew about anesthesia. Most of our patients were from urban area this may explains the height in our patients' knowledge about anesthesia. In the present study high percent of participants $82.67 \%$ knew that anesthesiologist is a doctor, this in agreement with a study by Acosta-Martínez et al (2016)and Ahsan-ul-Haq et al (2004)where the percents in their studieswere 80\% and $82 \%$ respectively, also in many studies by lee et al (2014),Prasad and Suresh(2014) and Bhandary et al (2016) the percentswere74.8\%,75\%and 60\% respectively, however our results still higher. In other studies (Swinhoe et al, 1994; Khan et al, 1999),Pandyaet al, 2016; Irwin et al, 1998), the percent was around 30-35\%, whileitraised in Caribbean and Singapore studies toreach $59 \%$ and $65.8 \%$ respectively of patientsknew that anesthesiologist is a doctor [Hariharan et al, 2006; Chew et al, 1998), another study (Hariharan, 2009)recorded least percent, only 5.5 \% of patients knew that anesthesiologist is a qualified doctor.This low percent reflects very poor knowledge about anesthesiologists who really are.This may return to many reasons such as; patients choose surgeons not anesthesiologist because some patients think that anesthesiologist is surgeon's assistant, another reason is the short duration often spent between patient and anesthesiologist (Hariharan, 2009).In replay to the question about safety of anesthesia, $70.30 \%$ of patients realized that anesthesia was safe; this result is close to one study(Garry, 2001)where $76 \%$ of individuals felt anesthesia as safe, while in another study (Ahsan- Ul-Haq et al, 2004)only 40 thought anesthesia was safe. Although our result about safety of anesthesia seems to be good, much awareness still needed to patients, this will decrease their fears before surgery especially with the presence of developed anesthesia 
techniques. There are different types of anesthesia for different surgeries, but only $61.88 \%$ of our patients knew that. This percent was lower compared to many other studies (Prasad et al, 2014; Ahmad et al, 2011), where percentage were higher $73 \%$ and $82.4 \%$, however in other study(Kadriet al, 2014), it was found that $48.1 \%$ of patients were aware of the various types of anesthesia techniques, while in a study by Pandya et al (2016) 74\% did not know about different anesthesia techniques.Informed consent is a document signed by the patient, it is a medicolegal binding between doctor and patient (Prasad et al, 2014). In the current study, 72.77\% of participants knew that the consent is important and nothing will be performed unless patient signed it. In a study by Prasad and Suresh (2014), they found that $77 \%$ of patient knew about this consent, while lower percent 34.67\% was reported by Naithani et al (2007), however in another study (Pandya et al, 2016)57.69\% of patients had awareness about this consent. Anesthesiologist can manage all types of pain, this fact was known by $64.85 \%$ of our patients and $88.12 \%$ knew about painless labor, our results were close to a study by Prasad and Suresh (2014)who showed that 69\% knew the role of anesthesia doctor in managing pain and $72.5 \%$ knew about painless labor, while in a study by Ahsan-ul-Haq et al (2004)they found that only $34 \%$ knew about the role of anesthesiologist in managing pain. In Egypt(Swinhoe et al, 1994)only 4.3\% knew about pain clinic, while $77.14 \%$ did not know about this role of anesthesiologist and $11.4 \%$ knew about the painless delivery. These results in Egypt are similar to that byNaithani et al (2007) who reported $12.67 \%$ of individuals knew about painless labor whereas only $19.4 \%$ said post-operative pain management by anesthesiologists in another study (Bhandary et al, 2016). In Finland study (Tohmo et al, 2003) 36\% of patients did not know the role ofanesthesiologists in pain clinics. This results show the weak awareness of patients about the role of anesthesiologists postoperatively. In the current study, a question especial to female was asked, it was about preferring painless delivery, $88.72 \%$ of them said yes, only $11.28 \%$ chose the painful delivery, whereas $73 \%$ preferred painless delivery in another study (Prasad et al, 2014). Although $11.28 \%$ is very low percent in preferring painful delivery, the fear of female from anesthesia may be the reason, it is recommended for pregnant to visit anesthesiologist before delivery, so she can know more about anesthesia and feel safe, as a result she may choose the painless way. By comparing our results to the results of Prasad and Suresh (2014) regarding preoperative instruction that patients should follow and benefit by visiting the anesthesia stall at the mela, we found that our patients were more aware of the preoperative instruction $92.08 \%$ than the other study $81 \%$, whereas in the previous study more individuals get benefit by visiting anesthesia stall at the mela $92 \%$ than ours $72.77 \%$. Regarding to gender as a factor affect awareness of individuals about anesthesiologist role, there was no significant difference in this study between male and female except for question number 2 about anesthesiologist as being a doctor ( $p$-value $=0.048)$, actually more female knew that anesthesiologist was a doctor, but in the other questions there were no significant differences between the two genders. Gender had significant association with knowledge of patients about anesthesia was a doctor. In contrast to our study, it was reported no significant differences between gender when asked if anesthesiologist was a doctor (Khara et al, 2013).However it was mentioned that gender had significant association with knowledge of patients about anesthesia(Naod et al, 2016).

\section{Conclusion:-}

Awareness about the role of anesthesiologistsand anesthesia of patients in this studywas very good and promising, however good contact between patients and anesthesiologists preoperatively still required and period spent between them should be increased to raise patients' awareness and knowledge about anesthesia and anesthesiologists' roles. The good relationship between anesthesiologists and patients can remove any fear before operation, also increasing trust in anesthesiologist leads togood outcome of operation. Our patients had good awareness, but programmes of awareness and eduction still needed to cover all the area in society to reach the best results.

\section{References:-}

1. Acosta-Martínez, J., Guerrero-Domínguez, R., López-Herrera-Rodríguez, D. and Sánchez-Carrillo, F. (2016): The anaesthetist's role from the patient's perspective,Rev. Colomb. Anestesiol., 44(2):121-127.

2. Ahmad, I. and Afshan, G. (2011): Knowledge and attitudes of Pakistani women towards anaesthesia techniques for caesarean section. J. Pak Med. Assoc., 61:359-362.

3. Ahsan- Ul-Haq, M., Azim, W. and Mubeen, M. (2004): A survey of patients' awareness about the perioperative role of anaesthetists.Biomedica, 20.

4. Armitage, E.N. (1978): The public image of specialty [letter]. Anaesthesia, 33:64-5.

5. Baaj, J., Takrouri, M.S., Hussein, B.M. and Al Ayyaf, H. (2006): Saudi patients' knowledge and attitude toward anesthesia and anesthesiologists--A prospective cross-sectional interview questionnaire. Middle East J. Anesthesiol, 18:679-691. 
6. Bhandary, A., Pallath, N.M., Ramakrishna, M. and Shetty, S.R. (2016): A survey on patients' awareness about anesthesia and anesthesiologist. Ind. J. of Clin. Anaesthesia., 3(2):196-206.

7. Cheung, V., Critchley, L.A., Hazlett, C., Wong, E.L. and Oh T.E. (1999): A survey of undergraduate teaching in anaesthesia. Anaesthesia, 54:4-12.

8. Chew, S.T., Tan, T., Tan, S.S. and Ip-Yam, P.C. (1998): A survey of patents' knowledge of anaesthesia and perioperative care. Singapore Med. J., 39:399-402.

9. Cooper, G.M. and Hutton, P. (1995): Anaesthesia and the undergraduate medical curriculum. Br. J. Anaesth.,74:3-5.

10. Erden,I.A. and Tütüncü, R. (2012): Patients' knowledge and attitudes about the role of anesthesiologists in a military hospital. Journal of Clinical and Experimental Investigations, 3 (3): 313-317.

11. Garry, D.P. (2001): Defining moments in medicine, Anaesthesia. Medical J. of Anaes., 174: 17-18.

12. Hariharan, S. (2009): Knowledge and Attitudes of Patients Towards Anesthesia and Anesthesiologists. A Review.Anestesiaen México, 21(3): 174-178.

13. Hariharan, S., Merritt-Charles, L. and Chen, D. (2006): Patient perception of the role of anesthesiologists - A Perspective from the Caribbean. J. Clin. Anesth.,18:504-509.

14. Hennessy, N., Harrison, D.A. and Aitkenhead, A.R. (1993): The effect of the anaesthetist's attire on patient attitudes. Anaesthesia, 48:219-222.

15. Irwin, M.G. and Fung, S.K.Y. (1998): Patient's knowledge and attitude to anaesthesia. Hong Kong Med. J., 4:16-22.

16. Ismaeil, W.E. (2011): Awareness of the public about anesthesia and

17. anesthesiologists in Egypt. Ain Shams J. Anesthesiol.,4(2):25-33.

18. Jathar, D., Shinde, V.S., Patel, R.D. and Naik, L.D. (2002): A study of patients' perception about the knowledge of anaesthesia and anaesthesiologist. Indian J. Anaesth., 46(1):26-30.

19. Kadri,I.A., Haider,G., Memon,I. and Memon, W. (2014): Awareness of patients regarding anesthesia; attitude towards basic types of anesthesia techniques. Professional Med. J., 21(4): 782-787.

20. Keep, P.J. and Jenkins, J.R. (1978): As others see us. The patient's view of the anaesthetist. Anaesthesia, 33:4345.

21. Khan, F.A., Hassan, S. and Zaidi, A. (1999): Patients' view of the anesthetists in a developing country. J. Pak Med. Assoc., 49:4-7.

22. Khara, B.N., Rupera, K.B., Gondalia, K.R. and Kamat, H.V. (2013): knowledge about anesthesia and perception about anesthesiologists among patients at a rural tertiary care hospital: a cross sectional survey. National J. Of Med. Res., (4).

23. Lee, J.J., Lee, N.H., Park, C.M., Hong, S.J., Kong, M.H., Lee, K.H., et al. (2014): Public awareness about the specialty of anesthesiology and the role of anesthesiologists: a national survey. Korean J. Anesthesiol., 66(1): 12-17.

24. Naithani, U., Purohit, D. Bajaj, P. (2007): Public Awareness About Anaesthesia and Anaesthesiologist: A Survey. Ind. J. of Anaesthesia, 51 (5): 420-426.

25. Naod, B., Admasu, W. and Ahmed, Y. (2016): Patients' Knowledge and Attitude towards Anesthesia in TikurAnbesa Specialized Hospital. Int. J. Anesth. Res., 4(5): 229-235.

26. Pandya, K., Mehta, K. and Patel, K. (2016): Awareness regarding anaesthesiology and anaesthesiologists among general population in developing country- a cross sectional survey. Natio.J. of Comm.Med., 16: 7(6).

27. Pleuvry, B.J. and Bradshaw, E.G. (1982): The anaesthetist in the eyes of the public. Anaesthesia, 37:462-463.

28. Prasad, C.G.S. and Suresh, G. (2014): A survey on public awareness about the role of anesthesiologists. AinShams J. Anesthesiol., 7:456-459.

29. Ribeiro, C.S. and de Barros Mourão, J.I. (2015): Anesthesiologist: the patient's perception. Rev. Bras. Anestesiol., 65(6):497-503.

30. Sable, T. and Waghchoure, N.D. (2016): Patients and nurses knowledge and attitude regarding general anaesthesia and anesthesiologist. Sch. J. App. Med. Sci.,4(9A):3261-3265.

31. Swinhoe, C.F. and Groves, E.R. (1994):Patients' knowledge of anaestheticpractice and the role of anaesthetists. Anaesthesia. 49(2):165-66.

32. Tohmo, H., Pälve, H. and Illman, H. (2003): The work, duties and prestige of Finnish anesthesiologists: patients' view. Acta.Anaesthesiol Scand.,47:664-666. 